\title{
Comparison of oral and vaginal misoprostol after oral mifepristone in early medical abortion
}

\author{
Nithya J.*, Reddi Rani P.
}

Department of Obstetrics and Gynecology, Jawaharlal Institute of Postgraduate Medical Education \& Research (JIPMER), Puducherry, India

Received: 07 January 2017

Accepted: 08 February 2017

*Correspondence:

Dr. Nithya. J,

E-mail: nithya.ms2010@gmail.com

Copyright: () the author(s), publisher and licensee Medip Academy. This is an open-access article distributed under the terms of the Creative Commons Attribution Non-Commercial License, which permits unrestricted non-commercial use, distribution, and reproduction in any medium, provided the original work is properly cited.

\section{ABSTRACT}

Background: Abortions are still a major problem in developing countries contributing to significant maternal morbidity and mortality. WHO has reported that 53 million unplanned pregnancies result in termination each year. One third of these are performed under unsafe conditions. Deaths related to these accounts for up to about $20 \%$ of the maternal deaths that occur each year throughout the world. the main objective of the present study is to compare the efficacy, side effects and acceptability of oral and vaginal misoprostol after single oral dose of mifepristone in induction of abortion in pregnancy up to 63 days.

Methods: It was a prospective randomized trial of 100 healthy women opting for termination of pregnancy with ultrasound confirmed intrauterine gestation of less than or equal to 9 weeks who were randomized in to two groups. Mifepristone $200 \mathrm{mg}$ was administered on day one followed by $800 \mu \mathrm{g}$ of misoprostol orally or vaginally 48 hours later. They were reviewed on day 7 and day 14 by ultrasound for completeness of abortion. If abortion was incomplete or bleeding was excessive, surgical evacuation was performed.

Results: The two groups were comparable with respect to age, parity and gestational age. The mean induction abortion interval was 51.2 hours.98\% of the women in both the groups had complete abortion. Nausea (68\%) and vomiting $(58 \%)$ were more common in oral group. Diarrhoea $(60 \%)$ was common in vaginal group. None of them had fever. Mean duration of bleeding was 9 days. $92 \%$ of the women found the procedure to be highly acceptable and would recommend it to others.

Conclusions: Medical abortion with $200 \mathrm{mg}$ mifepristone in combination with $800 \mu \mathrm{g}$ of misoprostol either orally or vaginally 48 hours later was found to be safe, simple, effective, inexpensive, noninvasive and acceptable method.

Keywords: Induction abortion interval, Mifepristone, Misoprostol

\section{INTRODUCTION}

Abortions are still a major problem in developing countries contributing to significant maternal morbidity and mortality. WHO has reported that 53 million unplanned pregnancies result in termination each year. ${ }^{1}$ One third of these are performed under unsafe conditions. ${ }^{1}$ Deaths related to these accounts for up to about $20 \%$ of the maternal deaths that occur each year throughout the world. ${ }^{1}$
In India, despite liberalisation of rules for performing medical termination of pregnancy, illegal abortions continue to contribute significantly to maternal morbidity and mortality. Suction evacuation is still being preferred for terminating first trimester unwanted pregnancies. It requires dilatation of cervix and evacuation which is not always safe and is associated with cervical injury, cervical incompetence, uterine perforation, haemorrhage and sepsis. Hence nonsurgical methods of termination of early pregnancy are preferred. The commonly used drugs are mifepristone and misoprostol. Mifepristone, a 
norethindrone derivative, is a potent antiprogesterone which binds to progesterone receptors and counteracts the effect of progesterone. It also softens and dilates cervix causes luteolysis, increases uterine contractions and enhances sensitivity to prostaglandin administration. Misoprostol, a prostaglandin E1 analogue interact with myometrial cell receptors causing strong myometrial cell contractions leading to expulsion of embryonic tissue. It also causes cervical softening and dilatation.

Medical termination of pregnancy using a combination of mifepristone and misoprostol is a safe, effective alternative to suction evacuation in early abortion. Various routes of administration of misoprostol and various combination regimens of mifepristone and misoprostol have been investigated. Misoprostol is given either orally or vaginally, 36-48 hours after oral mifepristone. Studies have shown that the vaginal administration of misoprostol after mifepristone resulted in a higher complete abortion rate than oral misoprostol alone. This study was undertaken to compare the efficacy of oral and vaginal misoprostol after oral mifepristone in induction of abortion up to 63 days and to compare the side effects and acceptability of the drug regimen.

\section{METHODS}

This study was carried out in the department of obstetrics and gynaecology, Jawaharlal Institute of Postgraduate Medical Education \& Research (JIPMER) between September 2007- May 2009. One hundred women opting for termination of pregnancy (MTP) in the first trimester and fulfilling the inclusion criteria were included. They were randomized in to two groups of 50 each.

\section{Inclusion criteria}

- Women seeking MTP with ultrasound confirmed intrauterine gestation of less than or equal to 9 weeks.

\section{Exclusion criteria}

- Haemoglobin < $10 \mathrm{gm} \%$.

- Hypersensitivity to prostaglandins.

- Medical conditions like adrenal failure, liver disease, hypertension, bronchial asthma, heart disease.

\section{Drugs used}

- $\quad$ Mifepristone 200mg

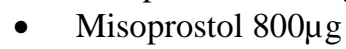

\section{Procedure}

The study comprised 100 healthy pregnant women requesting medical termination of pregnancy up to 9 weeks of gestation confirmed clinically and ultrasonographically. After an informed written consent, physical examination and base line investigations were carried out. Indication for MTP was noted. They were allocated to one of the two groups by computer generated random number table. Oral mifepristone $200 \mathrm{mg}$ was administered on day one of recruitment to all the women. If the abortion had not occurred by 48 hours, they were randomized to either oral or vaginal misoprostol group.

Group 1 (50) women were given $800 \mu \mathrm{g}$ of misoprostol orally. Group 2 (50) women were given $800 \mu \mathrm{g}$ of misoprostol vaginally.

They were observed for three hours (pulse, temperature, blood pressure, side effects and onset of bleeding) and sent home. The women were instructed to maintain a record of the following i.e., the time of abortion, number of days of bleeding and incidence of any possible side effects like fever, rigor, nausea, vomiting and diarrhoea. They were advised to report if bleeding did not begin 24 hours after the administration of misoprostol and an additional $400 \mu \mathrm{g}$ of misoprostol either orally or vaginally was administered.

All the women were reviewed on day 7 and day 14 for completeness of abortion by transvaginal ultrasound (TVS). If complete, the next visit was after the first menstrual period or at 6 weeks which ever was earlier. If abortion was incomplete or bleeding was excessive, surgical evacuation was done. Those opting for sterilization were treated as inpatients.

\section{Parameters studied were}

1. Complete abortion rate

- With mifepristone alone

- With oral misoprostol

- With vaginal misoprostol

2. Induction Abortion interval

3. Need for extradose of misoprostol

4. Need for check curettage

5. Frequency of side effects (nausea, vomiting, diarrhoea)

6. Duration of bleeding

7. Acceptability

8. Contraception

Successful medical abortions were those in which complete abortion occurred without any extra medical or surgical intervention. Failures were those in which either extra medical or surgical intervention was required. Statistical analysis was performed using SPSS software. Statistical tests like chi square test and t test were used.

\section{RESULTS}

The two groups were comparable with respect to age, parity and gestational age. $78 \%$ of the women in group 1 and $86 \%$ of the women in group 2 were in the age group of 21-30 years. $60-70 \%$ of the women were multigravida with two or more children. Most of the pregnancies were 
terminated between 49-63 days in both the groups. Gestational age was more than 49 days in $56 \%$ and $64 \%$ of the women in group1 and 2 respectively (Table 1).

Table 1: Demographic profile of both the groups

\begin{tabular}{|c|c|c|c|c|c|}
\hline \multirow{2}{*}{$\begin{array}{l}\text { Patient } \\
\text { characteristics }\end{array}$} & \multicolumn{2}{|c|}{$\begin{array}{l}\text { Group } 1 \\
(n=50)\end{array}$} & \multicolumn{2}{|c|}{$\begin{array}{l}\text { Group } \\
(n=50)\end{array}$} & \multirow{2}{*}{$\begin{array}{l}\mathbf{P} \\
\text { value }\end{array}$} \\
\hline & n & $\%$ & $\mathbf{n}$ & $\%$ & \\
\hline \multicolumn{6}{|l|}{ Age (years) } \\
\hline$<20$ & 3 & 6 & 1 & 2 & \\
\hline $21-25$ & 13 & 26 & 19 & 38 & \\
\hline $26-30$ & 26 & 52 & 24 & 48 & \\
\hline$>30$ & 8 & 16 & 6 & 12 & \\
\hline Mean & 27.14 & & 26.76 & & \\
\hline \multicolumn{6}{|l|}{ Gravida } \\
\hline 1 & 2 & 4 & 3 & 6 & \\
\hline 2 & 17 & 34 & 11 & 22 & \\
\hline$>3$ & 31 & 62 & 36 & 72 & \\
\hline \multicolumn{6}{|c|}{ Gestational age (days) } \\
\hline$<49$ & 22 & 44 & 18 & 36 & \multirow{2}{*}{0.159} \\
\hline $49-63$ & 28 & 56 & 32 & 64 & \\
\hline
\end{tabular}

The most common indication for termination was unwanted pregnancy $(80-88 \%)$ due to social reasons in multiparous women. The mean induction abortion interval in both groups was 51.2 hours. Range being 48.5 54 hours in both the groups. Mean dose of misoprostol required for successful abortion after pre-treatment with mifepristone was $800 \mu \mathrm{g}$ in both the groups (Table 2).

Table 2: Comparison of induction- abortion interval between the two groups.

\begin{tabular}{|l|l|l|l|l|l|l|}
\hline $\begin{array}{l}\text { Induction- } \\
\text { abortion interval } \\
\text { (hours) }\end{array}$ & \multicolumn{2}{l}{$\begin{array}{l}\text { Group 1 } \\
(\mathbf{n = 5 0})\end{array}$} & \multicolumn{2}{l|}{$\begin{array}{l}\text { Group 2 } \\
(\mathbf{n = 5 0})\end{array}$} & P value \\
\hline $24-49$ & 6 & 12 & 10 & 20 & \\
\hline $50-52$ & 39 & 78 & 36 & 72 & \multirow{2}{*}{0.51} \\
\hline$>52$ & 5 & 10 & 4 & 8 & \\
\hline Mean: 51.2 & & & & & \\
\hline Range: $48.5-54$ & & & & & \\
\hline
\end{tabular}

$98 \%$ of the women in both the groups had complete abortion. Only two women required additional intervention. One patient in group 1 required instrumental evacuation for retained products of conception. One patient in group 2 required additional $400 \mu \mathrm{g}$ misoprostol since the abortion process did not start 24 hours after $800 \mu \mathrm{g}$ misoprostol (Table 3).

Nausea and vomiting were more common in oral group accounting for $68 \%$ and $58 \%$ respectively which was statistically significant. Diarrhoea was common in vaginal group accounting for $60 \%$ and was statistically significant (Table 4). None of the woman had fever. There was no post procedural infection or sepsis in either group. None of the women required blood transfusion.
The mean endometrial thickness (ET) on day 7 and day 14 were $8 \mathrm{~mm}$ and $9.4 \mathrm{~mm}$ respectively. Mean duration of bleeding was 9 days with a range of 6-20 days. In our study $94 \%$ of the women had resumed menstruation during their first follow up visit and $59 \%$ of the women adopted contraception after a successful medical abortion. $92 \%$ of the women involved in the study found the procedure to be highly acceptable and would recommend it to others.

Table 3: Comparison of effectiveness of both the groups.

\begin{tabular}{|c|c|c|c|c|c|}
\hline & \multicolumn{2}{|c|}{$\begin{array}{l}\text { Group } 1 \\
(n=50)\end{array}$} & \multicolumn{2}{|c|}{$\begin{array}{l}\text { Group } 2 \\
(\mathrm{n}=50)\end{array}$} & \multirow[t]{2}{*}{$\begin{array}{l}\mathbf{P} \\
\text { value }\end{array}$} \\
\hline & $\mathbf{N}$ & $\%$ & $\mathbf{N}$ & $\%$ & \\
\hline $\begin{array}{l}\text { Complete } \\
\text { abortion }\end{array}$ & 49 & 98 & 49 & 98 & \multirow{6}{*}{0.278} \\
\hline Nullipara & 2 & 4 & 3 & 6 & \\
\hline Multipara & 47 & 94 & 46 & 92 & \\
\hline Failure & & & & & \\
\hline Nullipara & - & & - & & \\
\hline Multipara & 1 & 2 & 1 & 2 & \\
\hline
\end{tabular}

Table 4: Comparison of side effect profile following misoprostol.

\begin{tabular}{|l|l|l|l|l|l|}
\hline $\begin{array}{l}\text { Side } \\
\text { Effects }\end{array}$ & \multicolumn{2}{l}{$\begin{array}{c}\text { Group 1 } \\
(\mathbf{n = 5 0})\end{array}$} & \multicolumn{2}{l}{$\begin{array}{l}\text { Group 2 } \\
(\mathbf{n = 5 0})\end{array}$} & P Value \\
\hline Nausea & 34 & 68 & $\mathbf{N}$ & $\mathbf{\%}$ & \\
\hline Vomiting & 29 & 58 & 3 & 6 & $<0.05$ \\
\hline Diarrhoea & 2 & 4 & 30 & 60 & $<0.05$ \\
\hline
\end{tabular}

\section{DISCUSSION}

Various regimens of first trimester medical abortion are available now. Mifepristone followed by misoprostol 48 hours later has been in use for over a decade. The mifepristone misoprostol regimen has been found to be very effective and safe in the termination of early pregnancy. Regimens for medical abortion continue to evolve and are modified so as to provide best and safe option for the women seeking termination of pregnancy. Multicentre trials by WHO has shown that mifepristone $200 \mathrm{mg}$ is as effective as $600 \mathrm{mg} .^{2}$ It has been demonstrated that the oral misoprostol dose of $400 \mu \mathrm{g}$ is insufficient when the length of pregnancy is more than 7 weeks. $^{2}$ The success of medical abortion depends on various factors like the regimen used, dosage schedule, route of administration, gestational age.

In our study mean age of the patients in both the groups was 27 years which was comparable to similar other studies. ${ }^{2-4}$ There was no association between advancing maternal age and induction abortion interval or complete abortion rate. Multigravida accounted for $95 \%$ and parity did not influence the outcome whereas in a WHO multinational study, a double blinded randomized controlled trial of 2219 women with gestational age $\leq 63$ 
days, parity significantly affected the percentage of complete abortion. ${ }^{2}$ Nulliparous women had higher failure percentages than parous women. ${ }^{2}$ The most common indication for termination of pregnancy was unwanted pregnancy due to social reasons.

The mean gestational age was 47.68 days in group 1 (oral) and 50.24 days in group 2 (vaginal) and the range being 35-63 days. The success rate did not vary depending on the gestational age and route of administration in our study. WHO trial concluded that oral misoprostol is as effective as vaginal misoprostol with gestational age up to 56 days. Vaginal misoprostol is more effective than oral with gestation more than 56 days. $^{2}$

There are various studies using various doses of mifepristone and misoprostol. It has been found that low dose mifepristone $200 \mathrm{mg}$ with misoprostol $800 \mu \mathrm{g}$ is associated with higher success rate. ${ }^{5-8}$ In our study, mean Induction abortion interval was 51.2 hours i.e., 3.2 hours after $800 \mu \mathrm{g}$ misoprostol and the range was $48.5-54$ hours. This was comparable to the studies by Schaff et al and Ashok et al.,8 The route of administration of misoprostol had no effect on the initiation of bleeding and on the induction abortion interval. The mean Induction abortion interval was longer in women with gestational age>49 days but it was not statistically significant. In present study, mean dose of misoprostol required in both the oral and vaginal group was $800 \mu \mathrm{g}$. An additional $400 \mu \mathrm{g}$ was vaginally administered in group 2 as bleeding did not start 24 hours after $800 \mu \mathrm{g}$ misoprostol. Results of most of the studies indicate that $800 \mu \mathrm{g}$ of misoprostol administered 48 hours after $200 \mathrm{mg}$ mifepristone is ideal for induction of abortion up to 9 weeks. ${ }^{5,9,10}$

The complete abortion rate in our study was $98 \%$ in both the groups indicating that both oral and vaginal routes were equally effective. There was no relation between gestational age, route of administration and complete abortion rate in our study. None of the women expelled with mifepristone alone. Schaff et al in their randomized trial with a similar regimen as our study have found the complete abortion with oral group to $95 \%$ as against $99 \%$ in the vaginal group. ${ }^{4}$ Most of the studies have shown $97 \%$ complete abortion rate with $200 \mathrm{mg}$ mifepristone followed by $800 \mu \mathrm{g}$ vaginal misoprostol. ${ }^{5-9}$ Although the peak concentration after vaginal administration is lower when compared to oral, the bioavailability is higher which results in a higher success rate with vaginal route. In the present study, only two women (2\%) required additional intervention. The one in oral group required instrumental evacuation for retained products. The other in vaginal group required additional $400 \mu \mathrm{g}$ misoprostol with which she expelled the products of conception. This is comparable to similiar other studies. ${ }^{3,8,9}$

There were no major side effects like infection, sepsis or maternal death. The side effects were predominantly gastrointestinal symptoms. No women had severe blood loss which warranted transfusion. No women in our study reported fever which is one of the most common side effect of prostaglandins. In a study by Schaff et al ,291 women $(32.2 \%)$ had fever. ${ }^{6}$ In a study by $\mathrm{Li}$ et al,16\% of the women had fever. ${ }^{9}$ In a study by Schaff et al the women in vaginal group (32\%) had higher incidence of fever than oral group $(25 \%){ }^{4}$ Nausea and vomiting was seen in $68 \%$ and $58 \%$ of the women in oral group as against $22 \%$ and $6 \%$ in vaginal group and was statistically significant. Diarrhoea was seen in $60 \%$ of the women in vaginal group which was statistically significant. None of them required intravenous fluids or hospitalization. In a study by Schaff et al, nausea was common in oral group (51\%), diarrhoea was common in vaginal group $(33 \%)$ and vomiting was almost of equal incidence $(26 \%){ }^{4}$

Medical abortion results in longer duration of bleeding than surgical abortion. In our study mean duration of bleeding was 9 days with a range of 6-20 days. There was no difference between groups in the duration of bleeding among the women with complete abortion. It had no relation with the gestational age. In three multicentre studies by WHO, the mean duration of bleeding was 1112 days. ${ }^{2,11,12}$ Continuing oral misoprostol $400 \mu \mathrm{g}$ twice daily for 1 week did not influence on the amount or duration of postabortal bleeding, rather it produced more side effects. ${ }^{2,3}$ Ravn et al in his study defined successful abortion as an endometrial thickness $($ ET) $<20 \mathrm{~mm}$ by transvaginal ultrasound. ${ }^{13}$ In the present study, also the endometrial thickness was $<20 \mathrm{~mm}$ by TVS in women with complete abortion. The one with incomplete abortion had an ET of $30 \mathrm{~mm}$. The mean ET on day 7 and day 14 was $8 \mathrm{~mm}$ and $9.4 \mathrm{~mm}$ in both the groups respectively. $94 \%$ of the women had their menstruation at 6 weeks of follow up.

Counselling regarding contraception was offered to all women seeking medical abortion Intrauterine copper device was inserted in 12 women after resumption of their periods. Tubal ligation was done in 37 women following medical abortion. A major advantage is avoidance of any surgical procedure. Women who refused medical usually did so because it required too much time and too many visits. In our study, $92 \%$ of the women who underwent medical abortion found it to be acceptable which was comparable to a study by Schaff et al. ${ }^{6}$ Winikoff et al evaluated the acceptability of mifepristone and misoprostol regimen and found it was highly acceptable and $96 \%$ would recommend it to others, $91 \%$ would choose it again. ${ }^{14}$ Even among women for whom the method failed, $70 \%$ would try it again, $85 \%$ would recommend it to others.

\section{CONCLUSION}

Medical abortion with $200 \mathrm{mg}$ of oral mifepristone in combination with $800 \mu \mathrm{g}$ of misoprostol either by oral or vaginal route 48 hours later was found to be safe, simple, effective, inexpensive, non-invasive and acceptable 
method for induction of abortion in women with pregnancies up to nine weeks of gestation. The route of administration of misoprostol did not influence either the induction abortion interval or the complete abortion rates. Oral misoprostol was more acceptable because of the ease of administration.

\section{ACKNOWLEDGEMENTS}

Authors are thankful to the Dean and the Director, all the faculty members of the Department of Obstetrics and Gynaecology, JIPMER, Puducherry, India

Funding: No funding sources

Conflict of interest: None declared

Ethical approval: The study was approved by the Institutional Ethics Committee

\section{REFERENCES}

1. World Health Organization scientific group. Medical methods for termination of pregnancy: report of a WHO Scientific Group. World Health Organization technical report series. 1997;871:1-110.

2. World Health Organisation task force on post ovulatory methods of fertility regulation special programme of research, development and research training, World Health Organisation, Geneva. Comparison of two doses of mifepristone in combination with misoprostol for early medical abortion: a randomised trial. BJOG-Int J Obstet gynecol. 2000;107(4):524-30.

3. Mittal S, Agarwal S, Kumar S, Batra A. Comparison of oral versus vaginal misoprostol \& continued use of misoprostol after mifepristone for early medical abortion. Indian J Med Res. 2005;122:132-6.

4. Schaff EA, Fielding SL, Westhoff C. Randomized trial of oral versus vaginal misoprostol at one day after mifepristone for early medical abortion. Contracep. 2001;64:81-5.

5. Ashok PW, Penney GC, Flett GMM, Templeton A. An effective regimen for early medical abortion: a report of 2000 consecutive cases. Human Reproduc. 1998;13(10)2962-5.

6. Schaff EA, Eisinger SH, Stadalius LS, Franks P, Gore BZ, Poppema S. Low dose Mifepristone 200mg and Vaginal Misoprostol for abortion. Contracep. 1999;59:1-6.

7. Schaff EA, Fielding SL, Eisinger SH, Stadalius LS, Fuller L. Low dose mifepristone followed by vaginal misoprostol at 48 hours for abortion up to 63 days. Contracept. 2000;61(1):41-6

8. Ashok PW, Templeton A, Wagaarachchi PT, Flett GMM. Factors affecting the outcome of early medical abortion: a review of 4132 consecutive cases. BJOG-Int J Obstet gynecol. 2002;109(11):1281-9.

9. Li YT, Chen FM, Chen TH, Li SC, Chen ML, Kuo TC. Concurrent use of mifepristone and misoprostol for early medical abortion. Taiwan J Obstet Gynecol. 2006;45(4):325-8.

10. Guest J, Chien PF, Thomson MA, Kosseim ML. Randomised controlled trial comparing the efficacy of same-day administration of mifepristone and misoprostol for termination of pregnancy with the standard 36 to 48 hour protocol. BJOG-Int J Obstet gynecol. 2007;114(2):207-15.

11. World Health Organisation task force on postovulatory methods of fertility regulation. Medical abortion at 57 to 63 days gestation with a lower dose of mifepristone and gemeprost-a randomized controlled trial. Acta Obstet Gynecol Scand. 2001;80:447-51.

12. World Health Organisation Task Force on Postovulatory Methods of Fertility Regulation. Termination of pregnancy with reduced doses of mifepristone. BMJ. 1993;307:532-7.

13. Ravn P, Rasmussen A, Knudsen UB, Kristiansen FV. An outpatient regimen of combined oral mifepristone $400 \mathrm{mg}$ and misoprostol $400 \mu \mathrm{g}$ for first-trimester legal medical abortion. Acta Obstet Gynecol Scand. 2005;84:1098-02

14. Winikoff B, Ellertson C, Elul B, Sivin I. Acceptability and feasibility of early pregnancy termination by mifepristone-misoprostol. Results of a large multicenter trial in the United States. Mifepristone Clinical Trials Group. Arch Fam Med. 1998;7:360-6.

Cite this article as: Nithya J, Reddi RP. Comparison of oral and vaginal misoprostol after oral mifepristone in early medical abortion. Int $\mathbf{J}$ Reprod Contracept Obstet Gynecol 2017;6:1007-11. 